\title{
Regime Shifts Found in the Northern Hemisphere SST Field
}

\author{
Sayaka YASUNAKA and Kimio HANAWA \\ Department of Geophysics, Graduate School of Science, Tohoku University, Sendai, Japan
}

(Manuscript received 23 May 2001, in revised form 24 October 2001)

\begin{abstract}
A 'regime shift' is characterized by an abrupt transition from one quasi-steady climatic state to another, and its transition period is much shorter than the lengths of the individual epochs of each climatic state. In the present study, we investigate when regime shifts occurred and what was the difference in climatic states before and after the shifts, using the wintertime sea surface temperature (SST) field in the Northern Hemisphere. The relationship between changes in the SST field, and those in the atmospheric circulation, is also investigated.

In order to detect organized patterns of the SST variations, we apply an empirical orthogonal function (EOF) analysis. As the results, the first mode is identical to El Niño/Southern Oscillation (ENSO) and so-called Pacific Decadal Oscillation (PDO), and corresponds to the Pacific/North American (PNA) pattern. The second mode, which relates to the Arctic Oscillation (AO), has a zonally elongated signal in both the North Atlantic, and North Pacific. EOF analyses to each oceanic basin are made separately, and the robustness of these modes is confirmed.

In the present study, we define the regime shifts as the 'significant' and 'systematic' changes between the two quasi-steady states, continuing more than 5 years. Then, in order to identify the years when regime shifts occurred in the SST field, we carefully inspect the time series of original gridded SST data and those of the EOF modes. As a result, six regime shifts are detected in the study period from the 1910 s to the 1990 s: $1925 / 26,1945 / 46,1957 / 58,1970 / 71,1976 / 77$ and 1988/89. It is ascertained that the shifts at almost all grids are completed within one year. All regime shifts having similar SST and atmospheric circulation pattern, including the changes in an intensity of the Aleutian Low (AL), and the corresponding SST changes in the central North Pacific. All regime shifts can be well described by the combination of the first and the second EOF modes. The duration between each regime shift is about 10 years, which are identical to the PDO. The simultaneous shifts in the first, and the second EOF modes, imply that the change in the $\mathrm{AL}$ activity associated with the PNA pattern, might have some connection with that of the AO.
\end{abstract}

\section{Introduction}

The climate system in the North Pacific, and North Atlantic, represented by sea level pressure (SLP), and sea surface temperature (SST) fields, exhibits long-term variations with decadal or interdecadal time scales. Since the phase

Corresponding author: Sayaka Yasunaka, Department of Geophysics, Graduate School of Science, Tohoku University, Aoba-ku, Sendai 980-8578, Japan.

E-mail: yasunaka@pol.geophys.tohoku.ac.jp

(C) 2002, Meteorological Society of Japan reversals of such long-term variations appear like a step function rather than a sinusoidal one, these reversals are often called a 'climate jump', or a 'regime shift'. That is, a regime shift means an abrupt transition from one quasisteady climatic state to another, and this transition period is much shorter than the length of the individual epochs of each climatic state.

The regime shift in the mid 1970s is the most famous one and has been documented very well. After the 1976/77 regime shift, the tropical $\mathrm{Pa}-$ cific was warming, the central North Pacific was cooling, and at the same time, the Aleutian 
Low (AL) was strengthened (e.g., Nitta and Yamada 1989; Trenberth 1990; Tanimoto et al. 1993). These conditions lasted to the late $1980 \mathrm{~s}$ (Trenberth and Hurrell 1994). It is known that this regime shift occurred not only in the SST and atmospheric circulation fields, but also in the ecosystem in the North Pacific (e.g., Mantua et al. 1997). It is also pointed out that the similar regime shifts occurred in the 1920s, and the 1940s (Minobe 1997, 1999; Zhang et al. 1997).

Several studies argued that the regime shifts can be regarded as several periodic variations inherently existing in the climate system. Minobe (1999) insisted that the regime shifts observed in the North Pacific index (NPI; mean SLP anomaly in the central North Pacific in cooling season), resulted from simultaneous phase reversals between the pentadecadal (a period of about 50 years), and the bidecadal (about 20 years) oscillations. However, as pointed out by Zhang et al. (1997), each shift is not perfectly analogous to the others.

The abrupt transition of climate states has also been found in the North Atlantic. Actually, the North Atlantic Oscillation (NAO) index which is defined by the SLP difference between the Icelandic Low (IL) and the Azores High (AH), had a sharp reversal in the 1980s (Hurrell 1995).

In most of the previous studies, analyses of long-term SST variations have focused on each basin separately, and any attention has not been paid on the relationship between climate changes in the North Pacific and those in the North Atlantic. However, as pointed out by Yasunaka and Hanawa (2001), there exist the SST variations having signals both in the North Pacific and the North Atlantic, which is closely related to the activity of the Arctic Oscillation (AO). They also argued that this SST mode showed an abrupt change in the late 1980s.

In the previous studies, the regime shifts have also been detected by using several indices, such as the NPI, spatially averaged SST or records of fish stocks (e.g., Mantua et al. 1997; Minobe 1999; Hare and Mantua 2000). Although the usage of indices means that the spatial pattern associated with the regime shift is a-priori prescribed, there was no enough discussion whether these indices are suitable as the representation of the regime shifts or not. In the present study, in order to examine when regime shifts occurred, and what was the difference in climatic states before and after the regime shift without any assumption, we focus on the SST field instead of some indices.

In order to detect the 'significant' and 'systematic' regime shifts in the SST field, two different methods are applied. The first method is devoted to detect the year when significant shifts occurred in the large area of the SST field, without any prescribed spatial patterns due to the regime shift. The second method is to detect the year when large shifts occurred with the inherent spatial pattern of the SST variability using the empirical orthogonal function (EOF) modes. If the years of the regime shifts detected by both of the two methods are the same, we can say that the significant and systematic regime shifts occurred in those years. Then we describe characteristic patterns in these regime shifts.

Our investigation is made to the Northern Hemisphere SST field in winter, when an airsea interaction is most vigorous through the year. The relationship between changes in the SST field, and those in the atmospheric circulation, is also investigated.

The remainder of this paper is organized as follows. The data used are outlined in section 2 . In section 3, the results of an EOF analysis to the SST field, and regression analyses to the SST and the other atmospheric variables are described, preparatory to the detection of regime shifts. In section 4 , regime shifts are detected, and descriptions and trials of reconstruction of regime shifts are made. Section 5 gives our conclusions and discussions.

\section{The data used}

Various kinds of data are used in the present study: SST, SLP, $500 \mathrm{hPa}$ geopotential height, sea surface wind (SSW) and several indices representing atmospheric, or SST anomaly patterns.

The monthly mean $5^{\circ} \times 5^{\circ}$ (lat. $\times$ lon.) SST data are prepared by the authors. The data span the period from 1854 to 1997, but in the present study we use only the data after the 1910 s, when the data coverage spreads over basins along the main ship routes. The individual ship-reported SST data archived in 
the Comprehensive Ocean-Atmosphere Data Set (COADS; Woodruff et al. 1987), and in the recently released Kobe Collection (Manabe 1999), are used in computation. Although this SST dataset is covered in the world oceans, there are many blank grids, especially in the equatorial area and the oceans in the Southern Hemisphere in space and during the two World Wars in time. The details of data processing procedures of this new SST dataset are described in the appendix.

The monthly mean $5^{\circ} \times 5^{\circ}$ SLP data from 1899 to 1998 are those prepared by Miyamoto (2000). These SLP data are based on those originally complied by Trenberth and Paolino (1980). Although this original data have many blank grids, Miyamoto (2000) filled those blank grids using the technique developed by Ward (1989) for preparation of the Global Ice and Sea Surface Temperature (GISST) dataset.

The monthly mean $2.5^{\circ} \times 2.5^{\circ} 500 \mathrm{hPa}$ geopotential height data, are those of the National Center for Environmental Prediction (NCEP)National Center for Atmospheric Research (NCAR) reanalysis (Kalnay et al. 1996). The data cover the period from 1948 to 1998 .

The monthly mean $5^{\circ} \times 5^{\circ}$ SSW data used are those of the NCEP-NCAR reanalysis, and those produced by Hanawa and Yasuda (2000). The NCEP-NCAR reanalysis data (T62 Gaussian grid) cover globally, and the period from 1948 to 1998. This reanalysis data are resampled to a $5^{\circ} \times 5^{\circ}$ grid by using a Gaussian filter ( $e$-folding scale of $2.1^{\circ}$ ). When an analysis period expands prior to 1948, we use Hanawa and Yasuda (2000)'s SSW data, which are reconstructed using the SLP field. These data cover the North Pacific north of $20^{\circ} \mathrm{N}$ for the period from 1899 to 1995 . The details of this data can be referred to Hanawa and Yasuda (2000).

The monthly teleconnection pattern indices, such as the Pacific/North American (PNA) pattern index and the NAO pattern index from 1951 to the present, are cited from the web site of Climate Prediction Center (CPC) at NCEP (http://www.cpc.ncep.noaa. gov/data/teledoc/telecontents.html). These indices are the standardized amplitudes constructed from the leading modes of rotated EOF analyses for the $700 \mathrm{hPa}$ geopotential height fields for each month (Barnston and
Livezey 1987; Bell and Halpert 1995). We also use the AO index by Thompson and Wallace (2000) (http://www.atmos.colostate.edu/ao/Data/ ao_index.html), and the PDO index by Mantua et al. (1997) (http://tao.atmos.washington.edu/ data_set/pdo/). The AO index is the standardized time series of the leading EOF mode of monthly mean Northern Hemisphere SLP in the region north of $20^{\circ} \mathrm{N}$, using all months of the year. The PDO index is defined as the time coefficient of the leading EOF created from monthly SST anomalies poleward of $20^{\circ} \mathrm{N}$ in the Pacific basin.

In the present study, seasonal means are calculated from the monthly data. The winter is defined as the three months from January through March for the SST data. For the other atmospheric variables, on the other hand, the winter is defined as the three months from December through February, since these months correspond to the period having peak of winter conditions in respective fields.

\section{Dominant variations in the SST field and their relationships with the atmospheric circulation}

\subsection{EOF analysis to the SST field}

In order to detect organized patterns in the SST field and its relationship with the atmospheric circulation, an EOF analysis is applied by a covariance matrix method to the Northern Hemisphere SST field from the equator to $60^{\circ} \mathrm{N}$ in the North Pacific, and to $75^{\circ} \mathrm{N}$ in the North Atlantic (except for several grids in the higher latitudes and the central equatorial North Pacific having missing periods). The analysis period is 47 years from 1951 to 1997 when the data are filled at almost all grids over the study area.

Figures 1 and 2 show the standardized time coefficients of the first two EOF modes, and the distributions of regression and correlation coefficients of SST, SSW, $500 \mathrm{hPa}$ geopotential height and SLP with the standardized time coefficients of EOF modes.

The first EOF mode has a strong signal in the central North Pacific, and a signal with the sign reversed along the west coast of the North and South Americas extending over the equatorial Pacific in the SST field (Fig. 1(b)). The regression maps of $500 \mathrm{hPa}$ height and SLP show a series of positive and negative signals in 

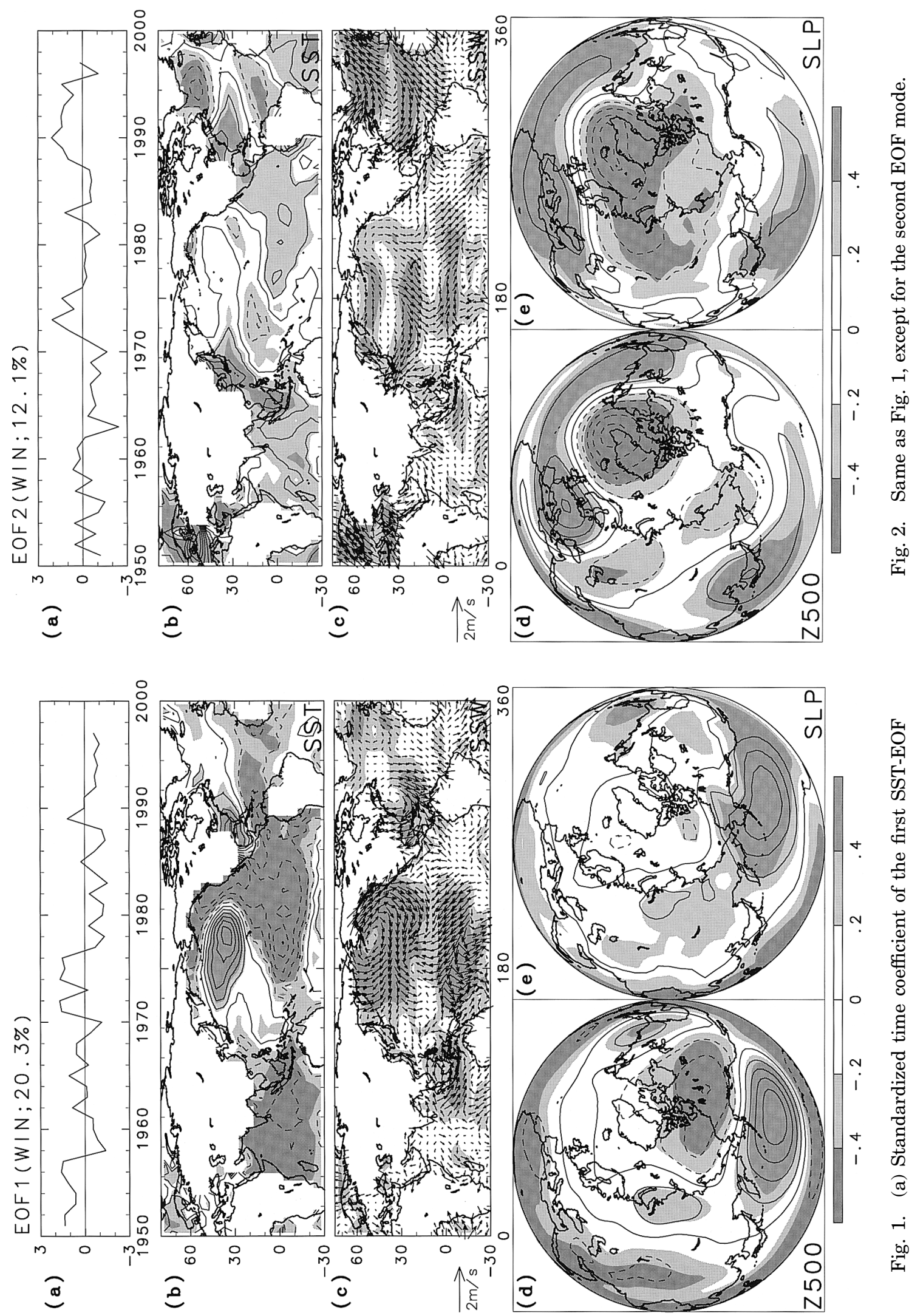

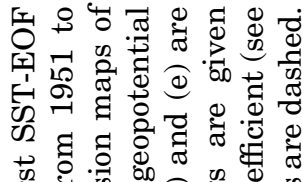

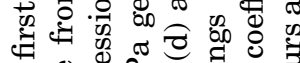

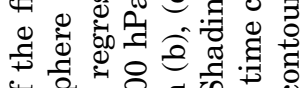
花象

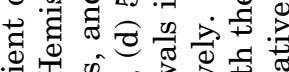

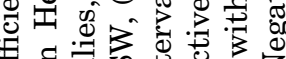

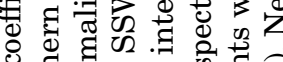

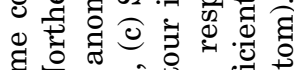

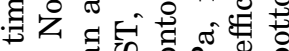

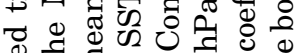

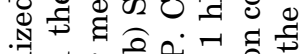

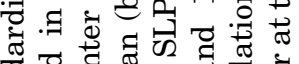

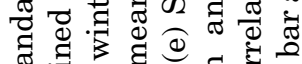

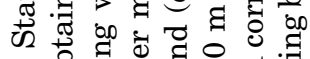
๙

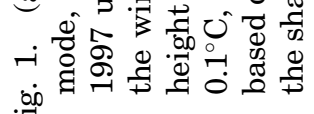
离 
turn from the subtropical North Pacific to the east coast of the United States (US), which is known as the reversed (anti-) PNA pattern (Figs. 1(d) and (e)). The time coefficient of the first mode (Fig. 1(a)) correlates well with the PNA index (correlation coefficient, $R=-0.55$ ). The regressed SSW field in the North Pacific shows anticyclonic feature corresponding to the weaker AL (Fig. 1(c)). This mode represents the so-called La Niña condition. Actually, the time coefficient correlates well with the Southern Oscillation index (SOI: difference of SLP between Darwin and Tahiti; $R=0.69$ ). The variation related to El Niño/Southern Oscillation (ENSO) phenomena in the tropical Pacific may have influenced on SST in the Indian Ocean, and the tropical Atlantic, through the 'atmospheric bridge' (Lau and Nath 1994).

The time coefficient of the first mode (Fig. 1(a)) has a longer time scale than ENSO time scale, since the abrupt changes are seen in the late $1950 \mathrm{~s}$, and the early and mid 1970s. It is consistent with the decadal variation found in the North Pacific referred as the Pacific Decadal Oscillation (PDO) at present (Tanimoto et al. 1993; 1997; Kachi and Nitta 1997; Mantua et al. 1997). Actually, correlation coefficient between the PDO index, and the time coefficient of this mode is 0.62 .

It is found that the first mode is also dominant even when an EOF analysis is applied to all months through the year (not shown; Nitta and Yamada 1989; Kawamura 1994).

The second EOF mode has a zonally elongated signal in the North Atlantic and the North Pacific; a negative signal in the higher latitudes, a positive in the mid latitudes, and a negative in the lower latitudes (Fig. 2(b)). The regression map of SLP shows the minimum in the polar region and the maximum in a zonal band with the sign reversed, which represents the stronger IL and $\mathrm{AH}$, and the weaker $\mathrm{AL}$ (Fig. 2(e)). This feature is very similar to that of the AO. Actually, correlation coefficient between the AO index and the time coefficient of this mode (Fig. 2 (a)) is 0.70 . The less zonally symmetric feature in the $500 \mathrm{hPa}$ geopotential height than that in the SLP field might be caused by the contamination of a baroclinic signature (Thompson and Wallace 1998). This mode is known to be the leading mode in the North Atlantic (e.g., Wallace et al. 1990; Deser and Blackmon 1993). On the other hand, the relationship between the NAO and the AO has been vigorously discussed as described in Yasunaka and Hanawa (2001). Although this subject is beyond our scope, it is worthy to note that correlation coefficient between the NAO index and the time coefficient of this mode is only 0.41 . That is, the AO as a hemispheric mode is more appropriate in interpretation of this mode.

The third mode is related to the north-south shift of the mid-latitude westerlies, and the fourth mode is related to an intensity of the mid-latitude westerlies (not shown here).

Eventually, we can say that the dominant EOF modes in the SST field correspond well to the specific atmospheric circulation patterns. In the next section, the EOF modes obtained here are used as the inherent organized variabilities in the SST fields.

\subsection{Confirmation of robustness of the EOF modes}

Since an EOF analysis is the method which detects dominant variations in the predetermined analysis domain, the results often depend on the selection of the analysis domain. If the analysis domain could be set just as the region where our target variation is embedded, then we might be able to detect the meaningful pattern-or it could happen. Other variations would contaminate, and the detected pattern would be skewed and meaningless. Therefore, the results described in the previous subsection should be checked by comparing them with those using different analysis domains.

In order to confirm robustness of the leading EOF modes in the previous subsection, EOF analyses are performed on the SST field in the North Pacific or the North Atlantic separately. Correlation coefficients of the time coefficients between the detected modes in the Northern Hemisphere and the North Pacific or the North Atlantic are listed in Table 1. The dominant modes in the Northern Hemisphere can be expected to obtain as the ones in the basin where the active (greater amplitude) areas of the modes exist. That is, the first and second modes of the Northern Hemisphere appear as the first mode of the North Pacific and the first mode of the North Atlantic, respectively. Further, the third (fourth) mode of the Northern Hemi- 
Table 1. Correlation coefficients between the time coefficients of leading EOF modes in the Northern Hemisphere $(\mathrm{NH})$, and those in the North Pacific (NP) and the North Atlantic (NA). Analysis period is 47 years from 1951 to 1997. Bold numerals with underline show correlation coefficients exceeding the $99 \%$ significant level by the Student $t$-test.

\begin{tabular}{l|cccc}
\hline & NP1 & NP2 & NP3 & NA1 \\
\hline NH1 & $\underline{-0.97}$ & 0.05 & 0.02 & 0.31 \\
NH2 & 0.05 & -0.43 & -0.43 & $\underline{0.83}$ \\
NH3 & -0.13 & $\underline{-0.83}$ & 0.08 & -0.33 \\
NH4 & 0.03 & -0.15 & $\underline{0.83}$ & 0.22 \\
\hline
\end{tabular}

sphere is identical to the second (third) mode of the North Pacific. Note that the dominant modes of the North Pacific also have some signals in the North Atlantic, and vice versa. Therefore it can be said that the leading EOF modes in the Northern Hemisphere are robust independent of the analysis domains.

\section{Detection of regime shifts and their description}

\subsection{Detection of regime shifts}

In the present study, we define the regime shifts as the 'significant' and 'systematic' changes between the two quasi-steady states in the SST field. The state continuing more than 5 years are regarded as the quasi-steady state. In order to detect the years when regime shifts occurred, we apply the following two methods.

In the first detection method, the years of the regime shifts are defined as the years when many grids showing significant jumps are found in the original gridded SST field. Using this method, we can detect the regime shifts without any prescribed spatial patterns due to the regime shift. On the other hand, in the second detection method, the years of the regime shifts are defined as the years when the time coefficients of the EOF modes obtained in the previous section change with significant jumps. Since the leading EOF modes have well organized patterns in the SST field, as described in the previous section, the significant jumps of the EOF modes can be considered to be systematic shifts in the SST field. If the years of the regime shifts detected by both of the two methods are same, then we can say that the 'significant' and 'systematic' regime shifts occurred in these years.

The difference between 5 -year means before and after a given year is used as a measure of jump. This averaging time of 5 years is chosen in order to reduce influences due to relatively higher frequency variations such as ENSO, which has a typical time scale of 3-4 years. On the other hand, if the averaging time is too long, there might be a possibility that two regime shifts are included in a given averaging time. Therefore, considering the relationship between decadal scale variation, and the regime shifts pointed out by several studies (e.g., Minobe 1999), a 5-year mean is valid. Filters in temporal domain are not used in these analyses, in order to take into account for some possibility that the regime shift appears like a step function, rather than a part of sinusoidal variations. Although we made the same analyses using 4-year and 6-year means, the results were not different.

\section{a. $\quad$ Detection using gridded SST time series}

First, we calculate the number of grids at which the difference between 5-year means before and after a given year changes at $90 \%$ significance level by the Student $t$-test. Since the number of data-filled grids shows a yearto-year variation, especially relatively small in number before the 1950 s, we calculate the percentage of the grids having significant difference to the data-filled grids instead of the number of grids itself. Figure 3 shows the 5year difference between the two 5-year means of $1972-76$ and $1977-81$ as an example. The number of data-filled grids is 712 , and that of grids showing significant difference is 324 , i.e. the percentage of grids showing the significance difference to the data-filled grids in 1976/77 is $45.5 \%$. Figure 4 shows time series of its percentage, and the mean percentage from 1954/55 to $1992 / 93(19.6 \%)$ when the data coverage is relatively better.

The years when percentage exceeds the mean value of $19.6 \%$ are selected as the years when significant differences occur in an extensive area, as shown by circles of the top row in Fig. 5. Closed circles in Fig. 5 denote the years having the maximum percentage in each cluster. 


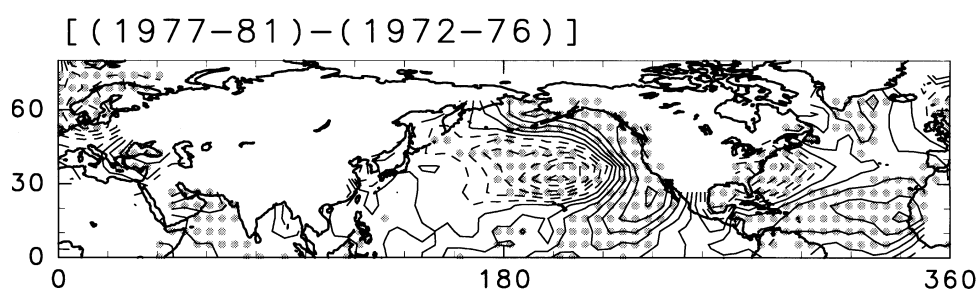

Fig. 3. Difference map of SST between the two 5-year periods of 1972-76 and 1977-81. Contour interval is $0.2^{\circ} \mathrm{C}$. Negative contours are dashed. Dots denote the grids which show the significant differences at the $90 \%$ significant level by the Student $t$-test.

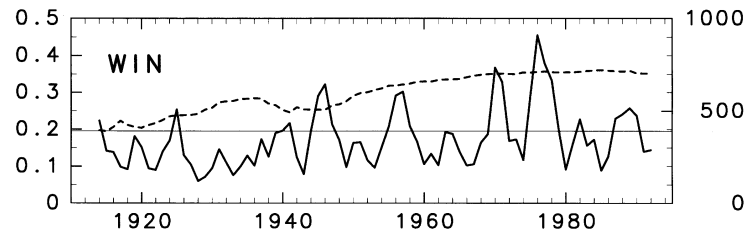

Fig. 4. Time series of ratio of the grids having significant differences of 5 -year means to the data-filled grids in the Northern Hemisphere SST field (thick line; left vertical axis). The number of the data-filled grids is shown by dashed line (right vertical axis; 823 grids exist in the calculation area). Horizontal line is the mean ratio of grids having significant difference from $1954 / 55$ to $1992 /$ 93.

\section{b. Detection using SST-EOF time series}

In this method, first the time coefficients of the first four EOF modes obtained in the previous section are extended until 1910 by a projection of SST onto the corresponding EOF spatial patterns, and then we calculate the difference between the 5-year means in the EOF time coefficients before and after a given year as the same way as in the first method. The result is shown in Fig. 6. Note that the time coefficients before 1950 are estimated assuming the spatial patterns of the dominant variations before 1950 are the same as those after 1951 .

The years when the differences of 5-year means exceed the mean magnitude of difference of the first EOF mode from 1954/55 to 1992/93 $(+/-2.4)$ (shown by thin horizontal lines in Fig. 6 ), are regarded as the years when the regime shifts might occur in the EOF modes, as shown by circles in Fig. 5 . Closed circles in Fig. 5 are also the years having the maximum and significant differences in each cluster.

c. Years of the regime shifts

Based on the analyses mentioned above, the years when the regime shifts occurred are designated as those concurrence of the largest differences (closed circles) observed in the gridded SST field and in the SST-EOF modes, that is, $1914 / 15,1925 / 26,1957 / 58,1970 / 71$ and 1976/77 as shown by the arrows in Fig. 5. In addition, 1945/46 is included, since both the gridded SST field, and the first and second EOF modes, have

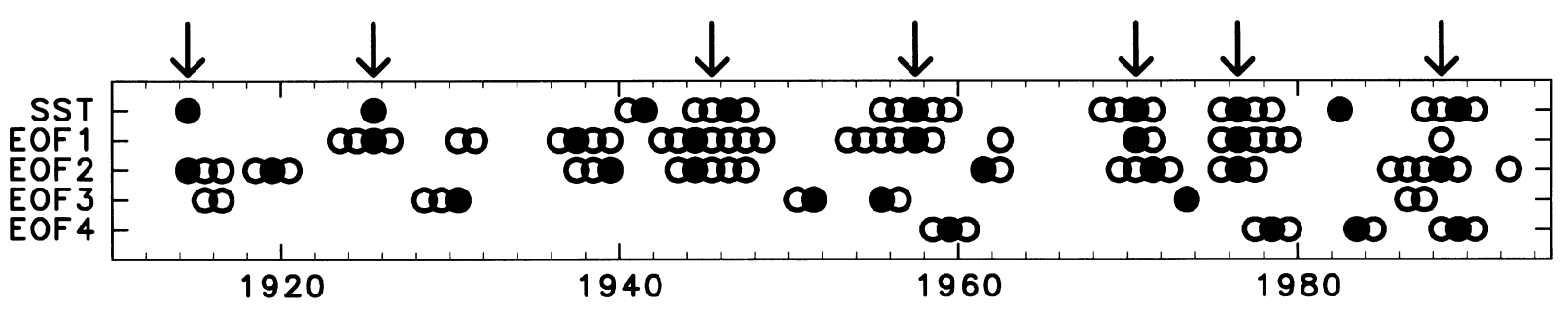

Fig. 5. Years when significant difference occurred in the SST field and the first four EOF modes. Closed circles denote the year showing the maximum difference in a cluster of significant difference years (open circles). The years shown by arrows are those designated as regime shifts at the present study, but in the later section the 1914/15 regime shift is discarded. 


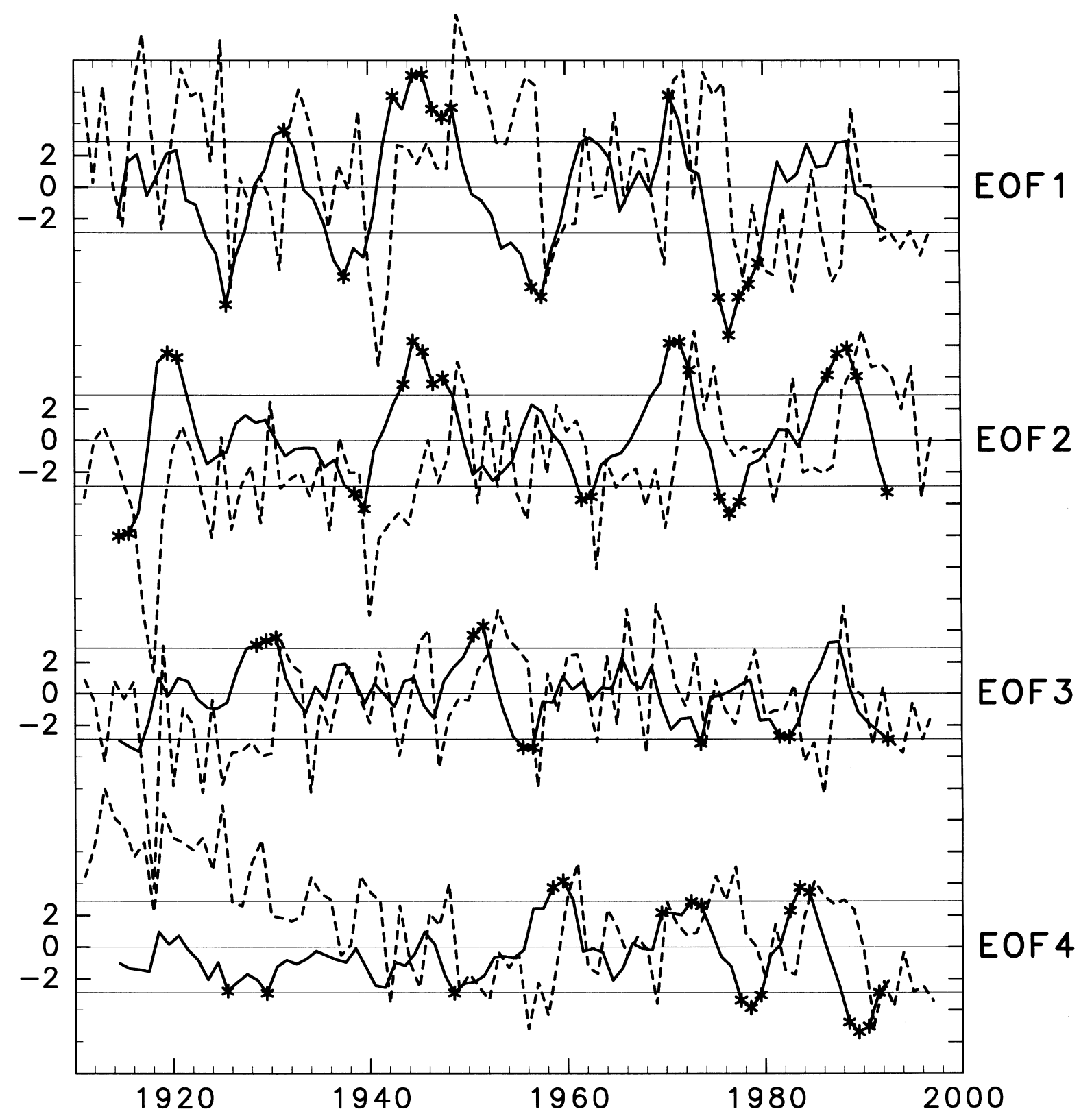

Fig. 6. Time coefficients of the first four SST-EOF modes (dashed lines) and time series of difference of 5-year means before and after each given year (solid lines). Time coefficients before 1950 are obtained by a regression analysis. Asterisks attached to solid lines show the years with differences exceeding the $90 \%$ significant level. Thin horizontal lines $(+/-2.4)$ denote mean value of difference time series in the first mode from 1954/55 to 1992/93.

differences as large as those in the maximum and significant years one year after or before. In the late $1980 \mathrm{~s}$, although the SST field and the fourth EOF mode have a maximum difference in 1989/90, we regard $1988 / 89$ as a regime shift since the first and second EOF modes also have a maximum difference at this year.

All of these shifts are found in both the first and second EOF modes, except for 1914/15 (only in the second mode), 1925/26 and 1957/58 
(only in the first mode) shifts. It means that differences in these regime shifts can be described by using the first and second EOF modes.

In order to examine whether these regime shifts occurred in the hemispheric scale or in each of the basin scales, the same analyses are performed both to the North Pacific and North Atlantic separately. In both of the basins, SST fields have large differences at the almost same years as those in the Northern Hemisphere, except for the 1914/15 shift which was not seen in the North Pacific, and the 1925/26 shift which was not seen in the North Atlantic.

As mentioned in section 3, the leading EOF mode associated with the regime shifts in each basin is only the PNA mode in the North Pacific and the AO mode in the North Atlantic. Therefore we can say that the regime shifts in the North Pacific are mainly associated with the PNA mode, and ones in the North Atlantic are mainly associated with the AO mode. However, since the regime shifts occurred in the North Pacific and North Atlantic at the same years, we should regard the regime shifts as the events of the whole hemispheric scale.

\subsection{Transient time of regime shift and reexamination of the regime shifts}

Prior to the discussion on the differences of SST and atmospheric conditions dividing by the specific regime shift, we further examine the transient time of regime shift. In addition, since the regime shifts were detected using 5 -year means in the previous subsection, we check again these regime shifts using means during the regimes from one regime shift to the next one, i.e., regime mean.

In order to examine the transient time, 1-year differences of SSTs, that is, SST differences between two successive years are calculated at the regime shifts detected in the previous subsection. As a result, it is found that percentages of the grids not having significant differences between 5-year differences and 1year differences are about $70 \%$ of the grids which showed the significant difference detected using 5 -year means. That is, it can be said that each regime shifts are completed within one year.

Next, we reexamine the regime shifts using regime means instead of 5-year means. In the
SST field, percentages of the grids having significant differences of regime means to the datafilled grids far exceed a measure of $19.6 \%$ used to detect the regime shifts (see Section 4.1), except for the 1914/15 shift (see the fifth column of Table 2). In addition, in time coefficients of the first and/or second EOF modes, six regime shifts-except for the 1914/15 shift-also show significant differences in regime means at $90 \%$ level (see the sixth and seventh columns of Table 2). Therefore it can be said that the conditions between the two regime shifts except for the 1914/15 shift, are in a quasi-steady state. Although the 1914/15 abrupt transition was detected using 5 -year means, the difference from the 1910-14 regime to the $1915-25$ one is not statistically significant. Therefore, in the present study, we do not regard the 1914/15 abrupt transition as a regime shift.

\subsection{Characteristic SST and atmospheric circulation pattern in the regime shifts and their reconstruction}

As described in the previous subsection, six regime shifts were detected during the period from the 1910 s to the 1990 s: $1925 / 26,1945 /$ 46, 1957/58, 1970/71, 1976/77 and 1988/89. In this subsection, we describe the characteristic pattern of SST anomalies and atmospheric conditions in each regime shift, and try to reconstruct them using SST-EOF modes and atmospheric circulation indices.

\section{a. Characteristic SST and atmospheric circulation pattern in the regime shifts}

Figures 7 and 8 show anomaly fields averaged during two regimes, i.e., 1971-76 and 1977-88 regimes. The $1971-76$ regime (Fig. 7) shows negative SST anomalies in the central North Pacific, and positive anomalies along the west coast of the US and in the tropical Pacific, with the weaker AL. In the Atlantic, SST anomalies are negative in the Northern Atlantic except for the east coast of the US, and positive in the Southern Atlantic, with the northsouth seesaw pattern in the pressure field with the stronger IL. On the other hand, since the magnitudes of anomaly fields are weaker, the 1977-88 regime (Fig. 8) is closer to the climatology than the 1971-76 one. In the North Pacific, SST anomalies are negative in the central and positive along the west coast of the US, with the stronger AL. 
Table 2. Summary of regime shifts detected and the results of reconstruction of regime shifts using the two leading EOF modes, and the PNA and the AO indices. Bold numerals with underline show those having difference magnitude exceeding the $90 \%$ significant level by the Student $t$-test. Percentage of variance (fourth column) is the ratio of variance accounted for by a step function for the two regimes to the total variance for the period of two regimes. Percentage of significant grids (fifth column) is the ratio of the grids having significant difference of means in regimes (regime mean) before and after the regime shift to the data-filled grids. Coefficients of two EOF modes (sixth and seventh columns) and two activity indices (ninth and tenth columns) denote the difference magnitude of means in regimes (regime means). Pattern correlation (eighth and eleventh columns) is the correlation coefficient between the SST difference map as shown in Fig. 9(a), and the SST reconstructed map as shown in Fig. 10(a).

\begin{tabular}{|c|c|c|c|c|c|c|c|c|c|c|}
\hline \multirow{2}{*}{$\begin{array}{c}\text { Regime } \\
\text { shift }\end{array}$} & \multirow{2}{*}{$\begin{array}{l}\text { Regime } \\
\text { (before) }\end{array}$} & \multirow{2}{*}{$\begin{array}{l}\text { Regime } \\
\text { (after) }\end{array}$} & \multirow{2}{*}{$\begin{array}{l}\text { Percentage } \\
\text { of variance }\end{array}$} & \multirow{2}{*}{$\begin{array}{l}\text { Percentage of } \\
\text { significant grids }\end{array}$} & \multicolumn{2}{|c|}{ Coefficients } & \multirow{2}{*}{$\begin{array}{c}\text { Pattern } \\
\text { correlation }\end{array}$} & \multicolumn{2}{|c|}{ Coefficients } & \multirow{2}{*}{$\begin{array}{c}\text { Pattern } \\
\text { correlation }\end{array}$} \\
\hline & & & & & EOF1 & EOF2 & & PNA & $\mathrm{AO}$ & \\
\hline $1914 / 15$ & $1910-14$ & $1915-25$ & 13.9 & 13.6 & -0.5 & -2.7 & 0.29 & & & \\
\hline $1925 / 26$ & $1915-25$ & $1926-45$ & 13.8 & 45.0 & $\underline{-4.7}$ & 0.8 & 0.40 & & & \\
\hline $1945 / 46$ & $1926-45$ & $1946-57$ & 14.6 & 33.1 & $\underline{5.5}$ & $\underline{3.0}$ & 0.74 & & & \\
\hline $1957 / 58$ & $1946 \cdot 57$ & $1958-70$ & 15.2 & 38.3 & $\underline{-5.8}$ & -1.5 & 0.77 & & & \\
\hline $1970 / 71$ & $1958 \cdot 70$ & $1971 \cdot 76$ & 21.6 & 43.1 & $\underline{6.2}$ & $\underline{4.6}$ & 0.86 & -0.4 & $\underline{1.2}$ & 0.75 \\
\hline $1976 / 77$ & $1971 \cdot 76$ & $1977-88$ & 26.8 & 48.3 & $\underline{-9.2}$ & $\underline{-3.2}$ & 0.93 & $\underline{1.3}$ & -1.0 & 0.82 \\
\hline 1988/89 & $1977-88$ & 1989-93 & 19.2 & 29.8 & $\underline{3.5}$ & $\underline{5.7}$ & 0.80 & -0.7 & $\underline{2.2}$ & 0.86 \\
\hline
\end{tabular}

Figure 9 shows the difference between the 1971-76 regime and the 1977-88 one (the latter minus the former), that is, changes occurred in the 1976/77 regime shift. In the SST field, negative changes are found in the central North Pacific and positive changes surround them. In the North Atlantic, negative changes are found along the east coast of the US, and there are positive changes in the rest of subtropics. The changes in the atmospheric field are characterized by the PNA pattern, with the intensifying AL. These features are consistent with those shown by such as Nitta and Yamada (1989) and Trenberth (1990). This regime shift represented as a step function can account for $26.8 \%$ (see the fourth column of Table 2) of total variance in the SST field for 18 years from 1971 to 1988.

The other five regime shifts also have the change of the AL, and the central North Pacific SST (not shown here). The polarities (sign of anomalies) of pressure fields in the AL region are the same as those of the polar region in the $1925 / 26$, and $1945 / 46$ regime shifts, while those in the other regime shifts are different. However, the results in the 1925/26 and 1945/46 shifts might not be confident enough because of a lack of the observational data in these period and region. In the North Atlantic, SST anoma- lies in the mid latitude zonally elongated, and reached the east coast of Europe in the 1957/58 and 1988/89 regime shifts, while SST anomalies with the same polarity spread out over the whole basin in the other regime shifts. The change in the tropical Pacific did not occur in the 1988/89 regime shift. According to spatial pattern correlation between SST difference maps of the regimes shifts (Table 3), it is found that the 1945/46, 1957/58, 1970/71 and 1976/77 regime shifts are similar pattern, while the 1925/26 and 1988/89 regime shifts are somewhat different.

The regime shifts detected in the present study correspond well to those in the previous studies. Mantua et al. (1997), and Minobe (1999) have pointed out that the regime shifts in the 1920s and 1940s included the change of an intensity of the AL. Although they argued that the change of the AL occurred three times in the 20th century (i.e., 1920s, 1940s and 1970s), however, the AL changes associated with the other regime shifts are not smaller in the present analysis. Different researchers have identified different years in middle of the 1940s as the year of the regime shift, e.g., 1942/43 in Zhang et al. (1997), and 1946/47 in Mantua et al. (1997). This can be considered due to the small number of data during the World War II. 

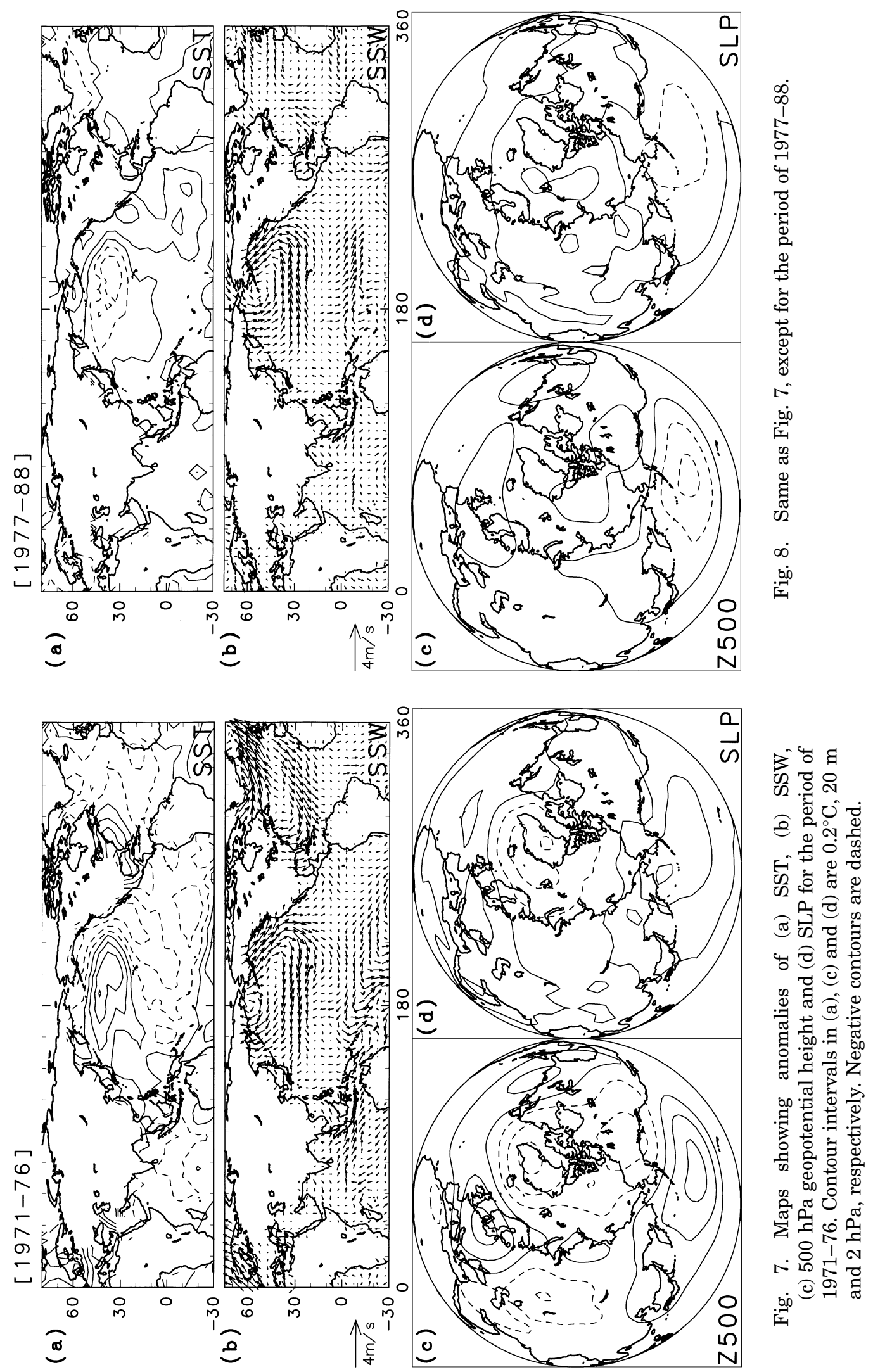


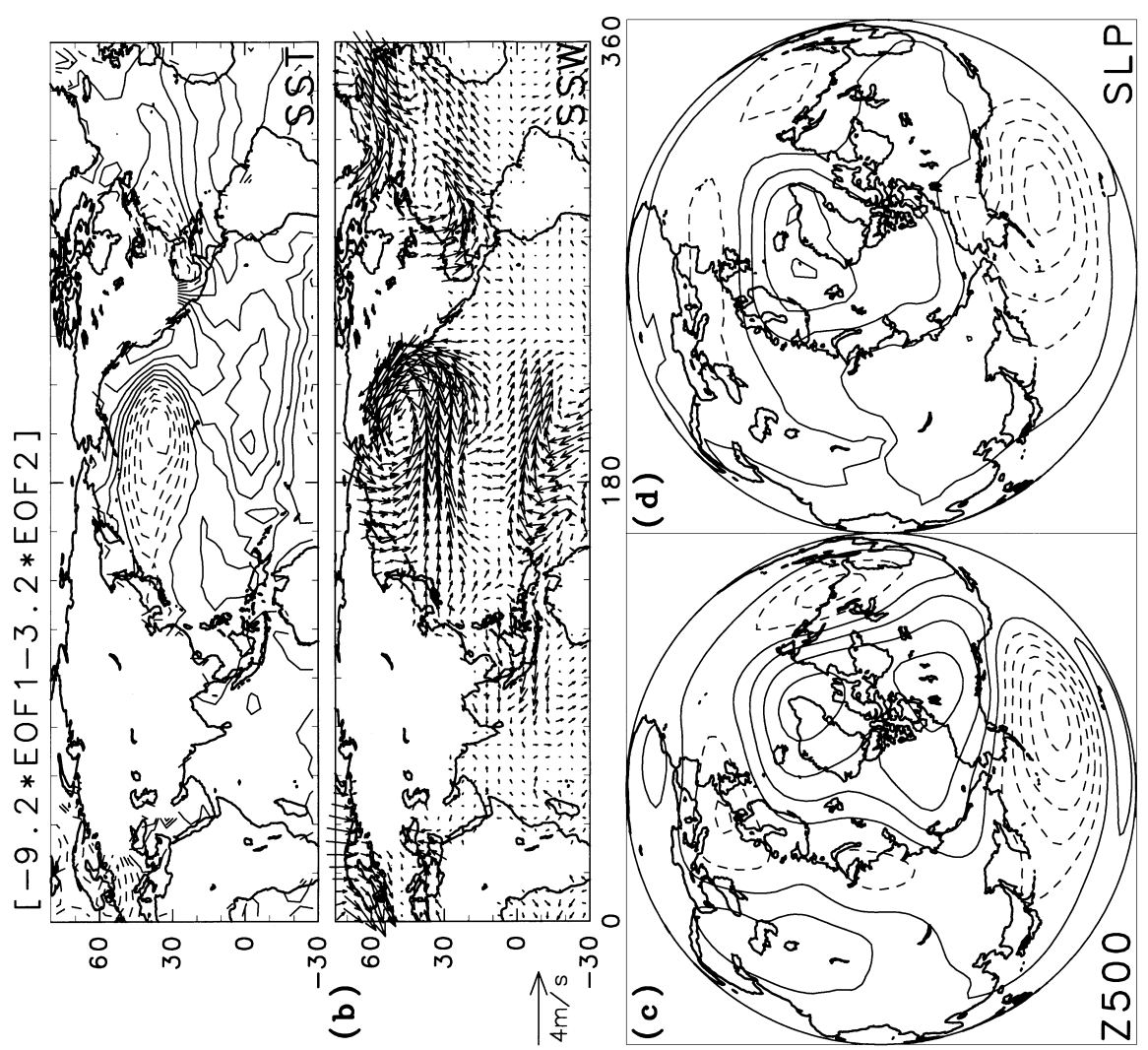

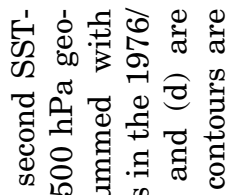

वृ

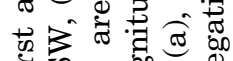

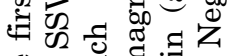

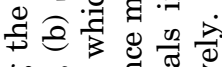

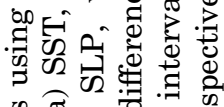

卷

है

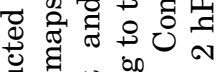

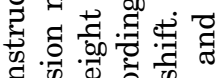

है क्ष

纯

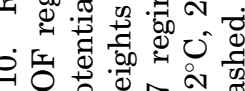

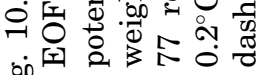

这

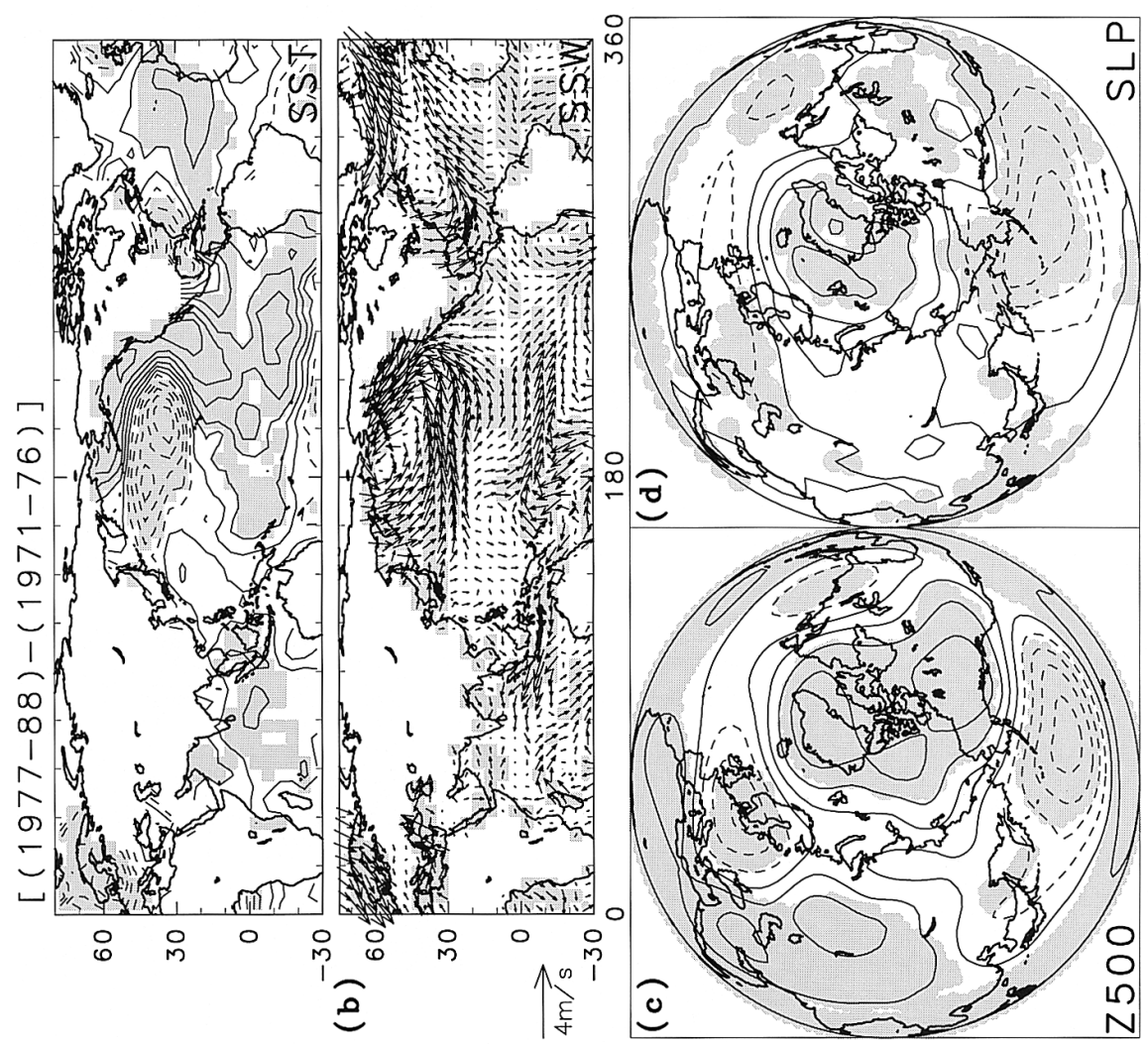

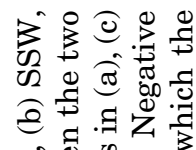

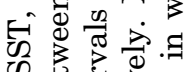

สิ

정

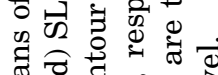

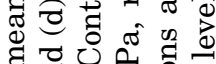

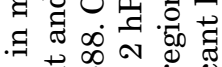

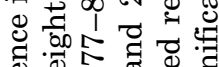

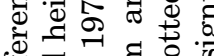

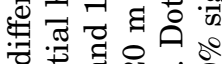

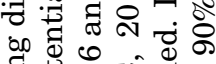

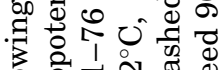

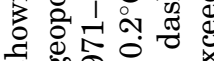

क 500 o

跑㟧

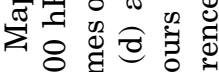

के

离金 
Table 3. Pattern correlation coefficients between the SST difference maps of the regime shifts.

\begin{tabular}{l|rrrrr}
\hline & $1945 / 46$ & $1957 / 58$ & $1970 / 71$ & $1976 / 77$ & $1988 / 89$ \\
\hline $1925 / 26$ & -0.38 & 0.36 & -0.45 & 0.52 & -0.39 \\
$1945 / 46$ & & -0.66 & 0.53 & -0.66 & 0.53 \\
$1957 / 58$ & & & -0.68 & 0.62 & -0.42 \\
$1970 / 71$ & & & & -0.81 & 0.57 \\
$1976 / 77$ & & & & & -0.57 \\
\hline
\end{tabular}

Overland et al. (1999) investigated SLP variation at the central part of the $\mathrm{AL}$, and detected several sign reversals during the 20th Century, most of which are consistent with the present study. The 1988/89 regime shift has a large change in pressure field in the polar region, which is accompanied by the abrupt decreasing of the sea-ice over the Sea of Okhotsk (Tachibana et al. 1996).

\section{b. Reconstruction of the regime shifts}

We try to reconstruct the regime shifts, using the regression maps of the first and the second SST-EOF modes (Figs. 1 and 2). Reconstructed maps are made by the superposition of the regression maps with weights according to the difference magnitudes in their EOF time coefficients. Figure 10 is an example of reconstruction of the 1976/77 regime shift $(-0.92 \times$ $\mathrm{EOF} 1+[-3.2] \times \mathrm{EOF} 2$; see Table 2 ). The features of these maps are quite similar to those of the difference maps shown in Fig. 9. Actually, spatial correlation coefficient between the SST difference map (Fig. 9(a)) and the reconstructed SST map (Fig. 10(a)) is 0.93 (see eighth column of Table 2). It is found that the other regime shifts except for the 1925/26 regime shift are also represented well by the reconstructed maps of the first and the second EOF modes as listed in Table 2. The reason why the 1925/26 regime shift could not be reconstructed well might be this regime shift had no strong signal in the North Atlantic (see subsection 4.1).

Further, we tried to reconstruct three regime shifts (1970/71, 1976/77 and 1988/89) using the atmospheric indices instead of the EOF modes, i.e. the PNA and the AO indices (the PNA index exists after 1951). The results show that the regime shifts are also reconstructed very well as shown in Table 2.

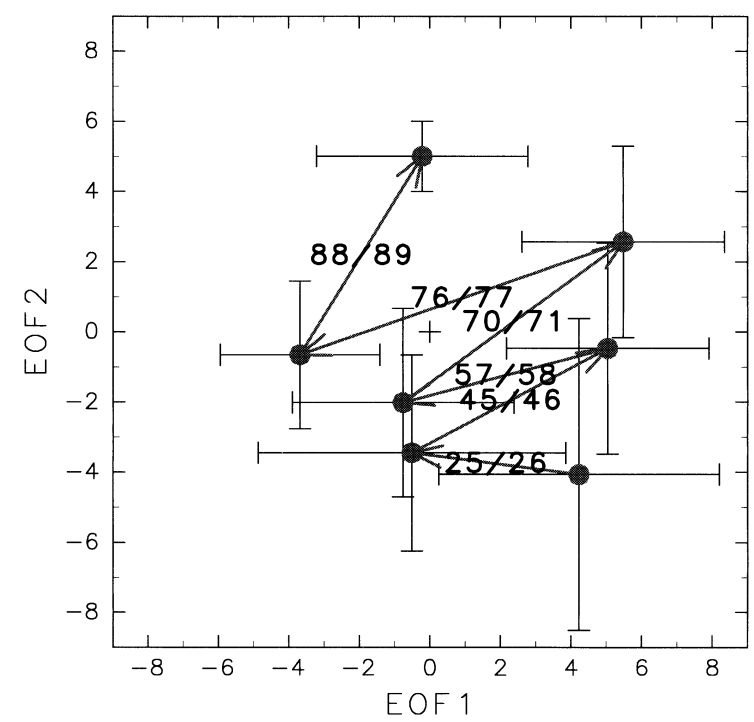

Fig. 11. Trajectory of the regime shifts on the diagram of the first and the second EOF time coefficients. Closed marks with vertical and horizontal bars denote the mean values between the regime shifts with the standard deviations.

Figure 11 shows a trajectory of the regime shifts represented by the time coefficients of the first and the second EOF modes. In the diagram, we can observe that for example, the 1976/77 regime shift is the one from a positive state in both the first and second modes to a negative state in the first mode, and an inactive (close to zero) state in the second mode. Therefore this regime shift can be mainly described by the first mode. Further almost all regime shifts, except for the 1925/26 regime shift tend to move along the one direction between the upper right corner and the lower left corner in the diagram. This tendency can clearly be seen in difference magnitudes of the first and second EOF modes corresponding to the regime shifts (see sixth and seventh columns of Table 2). That is, difference magnitudes of the first and second EOF modes have the same sign in all regime shifts, except for the 1925/26 regime shift. This means that the changes of the AL and SST in the North Pacific are enhanced by superposition of the two EOF modes.

\section{Conclusions and Discussions}

In the present study, six regime shifts were detected in the Northern Hemisphere SST field 
during the period from the 1910 s to the 1990 s. These are transitions from one quasi-steady climatic regime to another. The spatial patterns of the regime shifts are not perfectly identical with each other, but have a similar feature containing a change of the AL intensity. It was found that the first and the second SSTEOF modes, which correspond to the changes in activities of the PNA and the AO, could represent well all these regime shifts. This means that regime shifts occur as superposition of several unique modes (the first and the second EOF modes) of variabilities existing in the climate system.

A mechanism of a regime shift has not been understood yet. In order to explain the characteristics of a regime shift like a step function rather than a sinusoidal one, several studies argued that the climate could be considered to be a nonlinear dynamical system with chaotic attractors (e.g., Lorenz 1963). Actually, Hannachi (1997) proposed that in the North Pacific, the +/ - PNA could be regarded as two points of such chaotic attractors. Further, Corti et al. (1999) insisted that the PNA is one of the maximums of the probability density function in the state space of observational data. However, although the regime shifts detected in the present study are associated with the PNA activity, points corresponding with chaotic attractors cannot be found in the trajectory (see Fig. 11).

The duration between each regime shift is about 10 years, which are identical to the PDO. In addition, the PDO includes the change in the AL activity, which plays an important role of the PDO due to the tropical forcing through the atmospheric bridge (Gu and Philander 1997), or due to the local mid-latitude SST forcing (Latif and Barnett 1996). These imply the existence of some relationship between the regime shifts, and the PDO.

In the present study, we showed that shifts in the second SST-EOF mode reflecting the activity of the $\mathrm{AO}$ occurred simultaneously with shifts in the first mode. The AO is known to be the variation of the SLP field, coupled with the variation of the polar jet in the stratosphere (Thompson and Wallace 1998). Although the cause of the AO activity has not been clarified yet, Honda et al. (2001) suggested that the AL activity in early through mid winter could influence that of the AO. Therefore, the change in the AL activity associated with the PNA pattern might have some connection with that of the $\mathrm{AO}$, and we speculate that the $\mathrm{AL}$ is an important role in the regime shifts.

However, by the present study, we cannot understand the reasons why ratios between the difference magnitudes in the first and second EOF modes are not the same, rather depending on case-by-case (see the sixth and seventh columns of Table 2), and why the spatial patterns of the regime shifts are not perfectly identical with each other (see Table 3). More investigations are needed to clarify a relationship between the two EOF modes, and the regime shifts.

Finally, we would like to emphasize that in order to reveal the long-term climate variation the historical data are needed, as long and confident as possible. We hope that the present observations are maintained, and a digitization project to hidden historical data is encouraged.

\section{Acknowledgments}

The bucket correction values for historical SSTs are provided by the United Kingdom Meteorological Office, courtesy by Dr. D.E. Parker. Dr. K. Miyamoto kindly provided the SLP data. The authors thank the editor Dr. N. Iwasaka and two anonymous reviewers for their constructive comments. Thanks also extended to Dr. S. Minobe and the members of the Physical Oceanography Laboratory at Tohoku University for their fruitful comments and heartfelt encouragement. This study was made as part of the digitization project by the Japan Meteorological Agency and the Japan Weather Association, which was financially supported by the Nippon Foundation.

\section{Appendix SST data set}

Individual ship reports are used in calculation of grid point values of SST. The main source of raw data is COADS released by NOAA, U.S.A. The numbers of reports included in COADS gradually increase year by year, with two major data gaps in the periods encompassing World Wars I and II. In order to augment the raw data before World War II, the newly digitized Kobe Collection data are included in the calculation. The data processing 
procedures to obtain the gridded data set are as follows.

\section{Instrumental correction and elimination of erroneous data}

First of all, an instrumental correction, i.e., so-called bucket correction is made for the ship report taken before 1941 (Folland and Parker 1995; Hanawa et al. 2000). Further, in the ship reports of the whole period, those lower than $-2.5^{\circ} \mathrm{C}$ or higher than $40.0^{\circ} \mathrm{C}$ are discarded as erroneous data.

\section{Calculation of climatological 10-day mean values at $1^{\circ} \times 1^{\circ}$ box}

Climatological 10-day mean values, and the standard deviations at $1^{\circ} \times 1^{\circ}$ box, are calculated using the ship reports taken from 1961 to 1990 , when the data coverage is very well.

\section{Preparation of 'rough' climatological field}

For the gridded data (mean values and standard deviations) obtained in the previous step, in order to eliminate the erroneous gridded data, we adopt a median filter with a window of nine grids including the target grid itself in space and time (two grids east and west, one grid north and south, and one grid before and after in time). Here, when grids more than three among nine grids have values, then this procedure is actually applied. Then a median value of mean values and standard deviations is given to the target grid only when the value at the target grid is different by more than $5^{\circ} \mathrm{C}$ from the averaged value at the grids within the window for mean values, and by more than $1^{\circ} \mathrm{C}$ for the standard deviations.

In order to interpolate the mean and the standard deviation fields, the averaged value for surrounding nine grids are calculated by a binomial filter (1:4:6:4:1 in zonal direction, and $3: 6: 3$ in meridional and time directions). Here, when grids more than two among nine grids have values, then this procedure is actually applied and otherwise the target grid remains as blank.

These smoothing and interpolation processes are applied fifteen times to fill the values at all grids. The obtained 'rough' climatologies of mean values, and the standard deviations are used to eliminate the erroneous data in the next step.

\section{Elimination of erroneous data}

Individual ship reports during the whole period from 1854 to 1997 are checked using the mean values and the standard deviations, so-called three-sigma check. That is, the ship report whose anomaly from the 'rough' climatologies of mean values deviates beyond three times of the 'rough' climatologies of standard deviations is discarded.

\section{Preparation of climatologies}

Here again, using the data excluding the erroneous data, we calculate climatological 10day mean values for each $1^{\circ} \times 1^{\circ}$ grid from 1961 to 1990 as step 2 . The obtained climatologies of mean values are smoothed and interpolated using the same way as step 3.

\section{Interpolation and smoothing to 10-day and $1^{\circ} \times 1^{\circ}$ mean anomaly field}

Anomalies of individual ship reports from climatologies obtained in the previous step are calculated. Using these anomalies, 10-day and $1^{\circ} \times 1^{\circ}$ mean (gridded) anomalies are calculated through the whole period. In these anomaly fields, the grid whose mean anomaly exceeds $6^{\circ} \mathrm{C}$ is discarded, and set as blank. Then, the following interpolation and smoothing are applied.

In order to eliminate the erroneous gridded data, we adopt a median filter with a window of seven grids including the target grid itself in space and time (one grid east and west, north and south, and in time). When grids more than two among seven grids have values, then this procedure is actually applied, and a median value of mean values and standard deviations is given to the target grid only when the value at the target grid is different by more than $3^{\circ} \mathrm{C}$ from the averaged value at the grids within the window. Furthermore, the average values for the surrounding seven grids are calculated by a binomial filter. Weight of the target grid is 2, and that of the surrounding six grids is 1 . Here, when grids more than two among seven grids have values, then this procedure is actually applied, and a median value of mean values is given to the target grid.

\section{Analysis dataset}

In the present study, our interest is in basinscale variations with interannual or longer time scales. Therefore, 10-day mean $1^{\circ} \times 1^{\circ}$ 
gridded data are averaged into monthly mean $5^{\circ} \times 5^{\circ}$ gridded data, and interpolation and smoothing are applied again. Although many grids remain blank, especially in the early years and in the Southern Hemisphere, we did not apply additional interpolations, in order to avoid excessive smoothing, and to keep uniform accuracy independent from era and sea area.

\section{References}

Barnston, A.G. and R.E. Livezey, 1987: Classification, seasonality and persistence of lowfrequency atmospheric circulation pattern. Mon. Wea. Rev., 115, 1083-1126.

Bell, G.D. and M.S. Halpert, 1995: Atlas of intraseasonal and interannual variability, 19861993. NOAA Atlas No. 12, Climate Prediction Center, NOAA/NWS/MNC, Washington, DC.

Corti, S., F. Molteni and T.N. Palmer, 1999: Signature of resent climate change in frequencies of natural atmospheric circulation regimes. $\mathrm{Na}$ ture, 389, 799-802.

Deser, C. and M.L. Blackmon, 1993: Surface climate variations over the North Atlantic ocean during winter: 1900-1989. J. Climate, 6, 17431753.

Folland, C.K. and D.E. Parker, 1995: Correction of instrumental biases in historical sea surface temperature data. Quart. J. Roy. Meteor. Soc., 121, 319-367.

Gu, D. and S.G.H. Philander, 1997: Interdecadal climate fluctuations that depend on exchange between the tropics and extratropics. Science, 275, 805-807.

Hanawa, K. and T. Yasuda, 2000: Reconstruction of sea surface wind fields over the North Pacific using sea level pressure fields during the period of 1899-1995. J. Meteor. Soc. Japan, 78, 731-751.

_ S. Yasunaka, T. Manabe and N. Iwasaka, 2000: Examination of correction to historical SST data using long-term coastal SST data taken around Japan. J. Meteor. Soc. Japan, 78, 187-195.

Hannachi, A., 1997: Low frequency variability in a GCM: Three-dimensional flow regimes and their dynamics. J. Climate, 10, 1857-1379.

Hare, S.R. and N.J. Mantua, 2000: Empirical evidence for North Pacific regime shifts in 1977 and 1989. Prog. Oceanogr., 47, 103-145.

Honda, M., H. Nakamura, J. Ukita, I. Kousaka and K. Takeuchi, 2001: Interannual seesaw between the Aleutian and Icelandic low Part I: Seasonal dependence and life cycle. J. Climate, 13 (in press).
Hurrell, J.W., 1995: Decadal trends in the North Atlantic Oscillation: Regional temperatures and precipitation. Science, 269, 676-679.

Kachi, M. and T. Nitta, 1997: Decadal variations of the global atmosphere-ocean system. J. Meteor. Soc. Japan, 75, 657-675.

Kalnay, E.M., M. Kanamitsu, R. Kistler, W. Collins, D. Deaven, L. Gandin, M. Iredell, S. Saha, G. White, J. Woollen, Y. Zhu, M. Chelliah, W. Ebisuzaki, W. Higgins, J. Janowiak, K.C. Mo, C. Ropelewski, J. Wang, A. Leetmaa, R. Reynolds, R. Jenne and D. Joseph, 1996: The NCEP/NCAR 40-year reanalysis project. Bull. Amer. Meteor. Soc., 77, 437-471.

Kawamura, R., 1994: A rotated EOF analysis of global sea surface temperature variability with interannual and interdecadal scales. J. Phys. Oceanogr., 24, 707-715.

Latif, M. and T.P. Barnett, 1996: Decadal climate variability over the North Pacific and North America: Dynamics and predictability. J. Climate, 9, 2407-2423.

Lau, N.-C. and M.J. Nath, 1994: A modeling of the relative roles of tropical and extratropical SST anomalies in the variability of the global atmosphere-ocean system. J. Climate, 7, 11841207.

Lorenz, E.N., 1963: Deterministic nonperiodic flow. J. Atmos. Sci., 20, 130-141.

Manabe, T., 1999: The digitized Kobe Collection: Historical surface marine meteorological observations in the archival of the Japan Meteorological Agency. Bull. Amer. Meteor. Soc., 80, 2703-2715.

Mantua, N.J., S.R. Hare, Y. Zhang, J.M. Wallace and R.C. Francis, 1997: A Pacific interdecadal climate oscillation with impacts on salmon production. Bull. Amer. Meteor. Soc., 78, 1069-1079.

Minobe, S., 1997: A 50-70 year climatic oscillation over the North Pacific and the North America. Geophys. Res. Lett., 24, 683-686.

— 1999: Resonance in bidecadal and pentadecadal climate oscillations over the North $\mathrm{Pa}-$ cific: Role in climatic regime shifts. Geophys. Res. Lett., 26, 855-858.

Miyamoto, K., 2000: Reconstruction of sea surface wind and wind stress fields in the Northern Hemisphere during the last centenary. Doctoral Thesis, Tohoku University, 137pp.

Nitta, T. and S. Yamada, 1989: Recent warming of tropical sea surface temperature and its relationship to the Northern Hemisphere circulation. J. Meteor. Soc. Japan, 67, 375-383.

Overland, J.E., J.M. Adams and N.A. Boud, 1999: Decadal variability of the Aleutian Low and its relation to high-latitude circulation. J. Climate, 12, 1542-1548. 
Tachibana, Y., M. Honda and K. Takeuchi, 1996: The abrupt decrease of the sea ice over the southern part of the Sea of Okhotsk in 1989 and its relation to the recent weakening of the Aleutian Low. J. Meteor. Soc. Japan, 74, 579-584.

Tanimoto, Y., N. Iwasaka, K. Hanawa and Y. Toba, 1993: Characteristic variations of sea surface temperature with multiple time scales in the North Pacific. J. Climate, 6, 1153-1160. 1997: Relationship between sea surface temperature, the atmospheric circulation and air-sea fluxes on multiple time scales. J. Meteor. Soc. Japan, 75, 831849.

Thompson, D.J.W. and J.M. Wallace, 1998: The Arctic Oscillation signature in wintertime geopotential height and temperature field. Geophys. Res. Lett., 25, 1297-1300.

and 2000: Annular modes in the extratropical circulation. Part I: Month-to-month variability. J. Climate, 13, 1000-1017.

Trenberth, K.E. and D.A. Paolinio, 1980: The Northern Hemisphere sea level pressure dataset. Mon. Wea. Rev., 108, 855-872.
_ 1990: Recent observed interdecadal climate changes in the Northern Hemisphere. Bull. Amer. Meteor. Soc., 71, 988-993. and J.W. Hurrell, 1994: Decadal atmosphereocean variations in the Pacific. Clim. Dyn., 9, 303-319.

Wallace, J.M., C. Smith and Q.R. Jiang, 1990: Spatial patterns of atmosphere-ocean interaction in the Northern winter. J. Climate, 3, 990-998.

Ward, M.N., 1989: On the estimation of EOF time coefficients when data are missing. Meteorological Office Synoptic Climatology Branch Discussion Note 114.

Woodruff, S.D., R.J. Slutz, R.L. Jenne and P.M. Steurer, 1987: A comprehensive ocean-atomosphere data set. Bull. Amer. Meteor. Soc., 68, 1239-1250.

Yasunaka, S. and K. Hanawa, 2001: Arctic Oscillation and corresponding sea surface temperature anomaly fields. Tohoku Geophys. J., 36, 47-63.

Zhang, Y., J.M. Wallace and D.S. Battisti, 1997: ENSO-like interdecadal variability: 1900-93. J. Climate, 10, 1004-1020. 